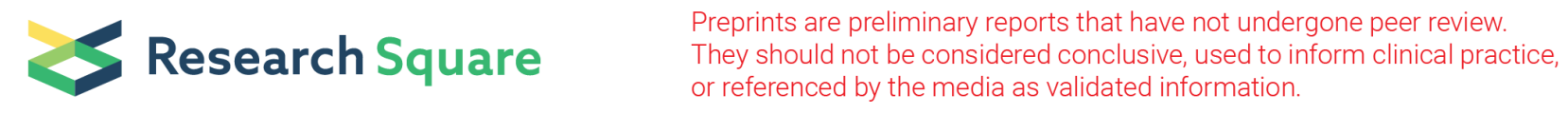

\title{
Metabolic-Related Index to Predict Post Transplantation Diabetes After Renal Transplantation
}

\author{
XIAOJIE NI \\ First Affiliated Hospital of Wenzhou Medical University \\ Yonglin Li \\ First Affiliated Hospital of Wenzhou Medical University \\ Tingting Huang \\ First Affiliated Hospital of Wenzhou Medical University \\ Yi Zhou \\ First Affiliated Hospital of Wenzhou Medical University \\ Bicheng Chen ( $\nabla$ chenbicheng@hotmail.com) \\ First Affiliated Hospital of Wenzhou Medical University
}

\section{Research Article}

Keywords: Post transplantation diabetes mellitus, Triglyceride, High-density lipoprotein cholesterol, Insulin resistance

Posted Date: February 15th, 2021

DOI: https://doi.org/10.21203/rs.3.rs-190909/v1

License: (c) (i) This work is licensed under a Creative Commons Attribution 4.0 International License. Read Full License 


\section{Abstract}

Background Early identification of post-transplantation diabetes mellitus (PTDM) can be helpful to attenuate the rapid development of diabetic complications. This article aims to explore the beneficial values of metabolic-related markers, including TyG, TyG-BMI, TG/HDL-C and non-HDL-C/HDL-C, for predicting PTDM.

Material and methods The data of 191 renal transplant recipients in our center were collected retrospectively. The association between the metabolic-related markers and the risk of PTDM was examined by the area under the curve and logistic regression analyses.

Results During 6 months follow-up, 12.04\% of RT recipients developed PTDM, and significantly higher values of TyG-BMI, TyG and non-HDLC/HDL-C was found in patients with PTDM than in nondiabetic patients, especially among the recipients taking FK506. The incidence of PTDM increased along with the values of TyG or TyG-BMI. After adjusting for multiple potential factors, recipients with the highest trisector of TyG or TyG-BMI still had a higher risk of PTDM morbidity.

Conclusions TyG, TyG-BMI, TG/HDL-C and non-HDL-C/HDL-C can predict PTDM in renal transplant recipients, and TyG-BMI was the best alternative marker among the four markers. TyG and TyG-BMI can be used as cost-effective and complementary monitors to identify individuals at high risk of PTDM.

\section{Introduction}

Renal transplantation (RT) is the best renal replacement therapy for end stage renal disease, but post-transplantation diabetes mellitus (PTDM), one of common complications of RT, can adversely affects both short-term and long-term outcomes of RT recipients [1]. The incidence of PTDM ranges between $4 \%$ and $39 \%$, and most PTDM is diagnosed in the first-year posttransplant [2,3]. PTDM can lead to adverse diabetes-related outcomes at a faster rate and early development of PTDM is associated with up to a 3-fold greater risk of cardiac events than nondiabetic recipients ${ }^{[2]}$. So early identification and treatment of PTDM is pivotal to attenuate the rapid development of diabetic complications. Insulin resistance (IR) and defective insulin secretion [4] are two main pathogeneses of PTDM. IR has been reported to be associated with an increased risk of progressive diabetic nephropathy [5]. The frequency of IR was found to be as high as $30 \%$ in stable RT patients, which is nearly three times the incidence in the general population. IR can be recognized as an early and strong predictor of PTDM even in the absence of hyperglycemia. Thus, the detection of IR can be helpful to predict the onset of PTDM.

However, the methods of estimating IR remain a challenge in clinical practice. The hyperinsulinemic-euglycemic clamp test is an acknowledged gold standard method for measuring IR [6], but complex operations and high costs restrict its clinical applicability. The homeostasis model assessment of insulin resistance index (HOMA-IR) is a commendable alternative indicator of IR, but the measurement of insulin required for HOMA-IR has been unstandardized and has poor repeatability. Recently, various metabolic risk factors such as the triglyceride-glucose index (TyG), TyG-body mass index (TyG-BMI), triglyceride/ high-density lipoprotein cholesterol ratio (TG/HDL-C) and nonhigh-density lipoprotein cholesterol/ high-density lipoprotein cholesterol ratio (non-HDL-C/HDL-C) have been suggested as simple and economical surrogate markers of IR. In both healthy subjects and abnormal glucose metabolism patients, TyG, TyG-BMI, TG/HDL-C and nonHDL-C/HDL-C had a high sensitivity and specificity for recognizing IR in previous studies [7,8]. However, the association between metabolicrelated markers and PTDM has not reached a consensus until now, so the aim of this article was to explore the beneficial values of metabolic-related markers, including TyG, TyG-BMI, TG/HDL-C and non-HDL-C/HDL-C, for predicting PTDM pretransplantation and earlystage posttransplantation.

\section{Methods}

\section{Subjects}

We retrospectively collected the data of RT recipients who received renal transplantation in our center between January 1, 2015 and December 31, 2019.The study subjects contained 31 living-related RT patients (16.23\%), 2 second RT patients (1.05\%), 33 chronic viral hepatitis B patients (17.28\%) and 1 chronic viral hepatitis C patient (5.24\%). The excluding criteria were as follows: (1) age younger than 18 or older than 80 years. (2) no available data on key variables, including fasting blood glucose (FBG), triglyceride (TG), high-density lipoprotein cholesterol (HDL-C), total cholesterol (TC), weight and height; (3) familial hypertriglyceridemia pretransplant; (3) triglycerideslowering drug use during the first 3 months posttransplant; (4) major adjustment of the immunosuppressive regimen or sirolimus use during the follow-up period; and (5) noncompliant patients. Finally, a total of 191 subjects, including 129 males and 62 females between 19 and 75 years old were selected in the present study and followed up for at least 6 months. 
Subjects were divided into three groups according to the status of diabetes mellitus (DM): the NC group (patients with no DM), PTDM group (patients with PTDM) and DM group (patients with DM pre-transplantation). Moreover, on the basis of the type of CNI, subjects were also divided into the FK506 subgroup and the CsA subgroup.

Ethics approval for the study protocol was obtained from the Medical Ethics Committee of The First Affiliated Hospital, Wenzhou Medical University. The research was conducted in accordance with the Declaration of Helsinki, and all participants provided written informed consent.

\section{Measurements}

The study subjects were followed monthly from RT surgery to at least 6 months posttransplant. Medical history information including age at RT, primary nephropathy, donor source, weight, height, and use of immunosuppressants was reviewed. Smoking history was defined as at least one cigarette per day for at least one year, and drinking history was defined as at least 1 drink per day for at least one year [9]. Weight was measured when patients wore light clothing to the nearest $0.1 \mathrm{~kg}$, and height was measured without shoes to the nearest $0.1 \mathrm{~cm}$. Body mass index (BMI) was calculated as weight $(\mathrm{kg})$ divided by height $(\mathrm{m})$ squared. Blood pressure (BP) was measured twice on the right arm while the subjects were in a seated position after at least 10 minutes of rest, and the average of the BP readings was calculated as the final result. Blood samples were obtained from the antecubital vein after fasting for at least 8 hours using BD vacutainer tubes containing EDTA and analyzed in our central laboratory under strict quality control. FBG, TG, TC, LDL-C, high-density lipoprotein cholesterol (HDL-C), serum creatinine (SCr), albumin (ALB), alanine aminotransferase (ALT), glutamine aminotransferase (AST), gamma-glutamyl transferase ( $\mathrm{Y}-\mathrm{GT}$ ) and hemoglobin (HB) were tested using a Beckman Coulter chemistry analyzer AU5800 (U.S.A.) and Sysmex XE2100 hematology analyzer (Japan). The formulas for estimated glomerular filtration rate (eGFR), non-HDL-C, TyG and TyG-BMI are listed as follows: eGFR $(\mathrm{ml} / \mathrm{min} / 1.73 \mathrm{~m} 2)\left(\right.$ Chinese modified MDRD equations) $=186 \times(\mathrm{SCr} \text { in enzymatic method })^{\wedge}-1.154 \times$ age ${ }^{\wedge}-0.203(\times 0.742$, if female $)$; nonHDL-C = TC - HDL-C; TyG = In [fasting TG (mg/dl) $\times$ FBG (mg/dl)/2] [10]; TyG-BMI = TyG index $\times$ BMI [11]. In addition, TG/HDL-C ratio and non-HDL-C/HDL-C ratio were calculated. Variables were collected at three time points: pretransplant, 1-month posttransplant and 3-month posttransplant.

\section{Definition of PTDM and obesity}

PTDM was diagnosed according to the criteria of the American Diabetes Association (ADA) as FBG $\geq 126 \mathrm{mg} / \mathrm{dl}$ (7.0 mmol/l) or 2-h blood glucose $(2 \mathrm{~h} \mathrm{BG}) \geq 200 \mathrm{mg} / \mathrm{dl}(11.1 \mathrm{mmol} / \mathrm{l})$ during a $75 \mathrm{~g}$ oral glucose tolerance test(OGTT) or glycosylated hemoglobin $\geq 6.5 \%$ (48 $\mathrm{mmol} / \mathrm{mol})$ or a random blood glucose $\geq 200 \mathrm{mg} / \mathrm{dl}(11.1 \mathrm{mmol} / \mathrm{l})$ in a patient with classic symptoms of hyperglycemia or hyperglycemic crisis. In the absence of unequivocal hyperglycemia, the diagnosis requires two abnormal test results from the same sample or in two separate test samples [12]. Subjects with $\mathrm{BMI} \geq 25 \mathrm{~kg} / \mathrm{m}^{2}$ were diagnosed as overweight.

\section{Statistical analyses}

The continuous variables were presented as the mean value \pm standard deviation (SD), and categorical variables were presented as frequencies and percentages. The normality of the parameters was verified using Kolmogorov-Smirnov tests. The means of continuous variables between groups were assessed by a one-way analysis of variance (ANOVA) with replicate measures, and a post hoc analysis of the least significant difference (LSD) was used when the means of the continuous variables were normally distributed; if not, the Tamhane's T2 test was used. The Student's t-test was used for two independent continuous variables, and the Chi-square test was used for categorical variables. According to trisections of each studied marker, the non-DM and PTDM subjects were divided into four groups, and the incidence of PTDM was compared between the four groups. The diagnostic accuracy of each studied marker in predicting PTDM was estimated using the AUC from the ROC curve, and an AUC >0.7 was considered a good predictive value. Youden's index was calculated as (specificity+ sensitivity-1) and then was used to determine the optimal cutoffs of the studied markers for predicting PTDM. A logistic regression model after adjustment for multiple confounders was built to calculate the odds ratios (ORs) and 95\% confidence intervals (Cls) of the studied markers. Model 1 was adjusted for sex and age; Model 2 was adjusted for sex, age, smoking, drinking, obesity, hypertension and viral hepatitis C; and Model 3 was further adjusted for CNI, TC, LDL-C, ALB, ALT, eGFR and Hb based on Model 2. Statistical analysis was carried out using SPSS version 22 and MedCalc Statistical Software version 18.2.1. Two-tailed $P<0.05$ was considered to be statistically significant.

\section{Results}

\section{Pretransplant demographic characteristics and laboratory data}


The pretransplant demographic characteristics and laboratory data of the study subjects are summarized in Table 1. Of the 191 subjects, the mean age was $43.12 \pm 11.87$ years with $67.54 \%$ (129/191) male. Patients with PTDM or DM were older and had higher $2 \mathrm{~h}-\mathrm{BG}$, higher BMI and higher HDL-C than nondiabetic patients. Patients with PTDM had the highest proportion of tacrolimus (FK506) usage and patients with DM had the highest proportion of overweight. BP, smoking and drinking history, TC, TG, LDL-C, FBG, SCr, eGFR, ALB, ALT, AST, Y-GT and HB were compared between the three groups but no significant differences were found.

Table 1. Comparisons of demographic characteristics of each group pretransplant.

\begin{tabular}{|c|c|c|c|c|c|}
\hline Variables & Total $(n=191)$ & $\mathrm{NC}(\mathrm{n}=145)$ & PTDM $(n=23)$ & $\mathrm{DM}(\mathrm{n}=23)$ & $P$ \\
\hline Age (years) & $43.12 \pm 11.87$ & $40.57 \pm 11.02$ & $47.91 \pm 10.23 a b$ & $54.35 \pm 10.89^{a}$ & 0.003 \\
\hline Male $(n, \%)$ & $129(67.54)$ & $95(65.52)$ & 19 (82.61) & 15 (65.22) & 0.260 \\
\hline FK506 (n, \%) & $134(70.16)$ & $116(80)$ & $13(56.52)^{a b}$ & $5(21.74)^{a}$ & $<0.001$ \\
\hline BMI $\left(\mathrm{kg} / \mathrm{m}^{2}\right)$ & $21.51 \pm 3.17$ & $20.87 \pm 2.98$ & $23.53 \pm 2.54^{\mathrm{a}}$ & $23.52 \pm 3.31^{\mathrm{a}}$ & $<0.001$ \\
\hline Overweight (n, \%) & $20(10.47)$ & $9(6.21)$ & $4(17.39)$ & $7(30.43)^{a}$ & 0.001 \\
\hline SBP $(\mathrm{mmHg})$ & $142.93 \pm 20.34$ & $141.23 \pm 18.98$ & $145.65 \pm 22.18$ & $150.96 \pm 25.04$ & 0.330 \\
\hline $\mathrm{DBP}(\mathrm{mmHg})$ & $87.95 \pm 13.20$ & $89.23 \pm 13.10$ & $85.81 \pm 12.62$ & $82.22 \pm 13.10$ & 0.218 \\
\hline $\operatorname{HBP}(n, \%)$ & 187 (97.91) & 144 (99.31) & 19 (82.61) & $23(100)$ & $<0.001$ \\
\hline Smoking (n, \%) & $61(31.94)$ & $45(31.03)$ & $6(26.09)$ & $10(43.48)$ & 0.403 \\
\hline Drinking $(\mathrm{n}, \%)$ & $34(17.80)$ & $20(13.79)$ & $3(13.04)$ & $6(26.09)$ & 0.300 \\
\hline $\mathrm{TC}(\mathrm{mmol} / \mathrm{L})$ & $4.39 \pm 1.25$ & $4.38 \pm 1.25$ & $4.51 \pm 1.05$ & $4.37 \pm 1.47$ & 0.653 \\
\hline TG (mmol/L) & $2.14 \pm 1.75$ & $1.95 \pm 1.47$ & $2.58 \pm 1.59$ & $2.87 \pm 2.97$ & 0.231 \\
\hline $\mathrm{HDL}-\mathrm{C}(\mathrm{mmol} / \mathrm{L})$ & $1.00 \pm 0.29$ & $1.03 \pm 0.30$ & $0.90 \pm 0.21^{a}$ & $0.94 \pm 0.30^{a}$ & 0.043 \\
\hline LDL-C (mmol/L) & $2.39 \pm 0.82$ & $2.40 \pm 0.83$ & $2.47 \pm 0.80$ & $2.24 \pm 0.76$ & 0.694 \\
\hline FBG (mmol/L) & $5.37 \pm 2.15$ & $4.80 \pm 0.76$ & $5.11 \pm 0.88$ & $9.24 \pm 4.18$ & 0.315 \\
\hline 2h BG (mmol/L) & $6.54 \pm 1.97$ & $5.83 \pm 1.04$ & $8.98 \pm 1.73^{a}$ & $12.35 \pm 3.59 \mathrm{ab}$ & 0.035 \\
\hline $\mathrm{SCr}(\mu \mathrm{mol} / \mathrm{L})$ & $885.77 \pm 289.67$ & $870.90 \pm 278.65$ & $965.48 \pm 327.56$ & $899.83 \pm 317.51$ & 0.147 \\
\hline eGFR $\left(\mathrm{ml} / \mathrm{min} / 1.73 \mathrm{~m}^{2}\right)$ & $5.90 \pm 2.41$ & $6.07 \pm 2.54$ & $5.18 \pm 1.96$ & $5.54 \pm 1.87$ & 0.101 \\
\hline ALB (g/L) & $41.09 \pm 5.60$ & $41.29 \pm 5.43$ & $39.06 \pm 5.71$ & $41.86 \pm 6.32$ & 0.075 \\
\hline $\operatorname{ALT}(\mathrm{U} / \mathrm{L})$ & $17.62 \pm 11.64$ & $17.62 \pm 11.87$ & $18.13 \pm 11.51$ & $17.13 \pm 10.74$ & 0.846 \\
\hline AST (U/L) & $17.64 \pm 8.12$ & $17.62 \pm 8.14$ & $17.78 \pm 7.93$ & $17.61 \pm 8.55$ & 0.930 \\
\hline $\mathrm{Y}-\mathrm{GT}(\mathrm{U} / \mathrm{L})$ & $26.68 \pm 19.27$ & $26.86 \pm 21.16$ & $24.35 \pm 9.10$ & $27.87 \pm 14.07$ & 0.564 \\
\hline $\mathrm{HB}(\mathrm{g} / \mathrm{L})$ & $112.49 \pm 19.78$ & $114.65 \pm 18.85$ & $106.30 \pm 13.81$ & $105.09 \pm 27.11$ & 0.058 \\
\hline
\end{tabular}

BMI: body mass index; SBP: systolic blood pressure; DBP: diastolic blood pressure; TC: total cholesterol; TG: total cholesterol; HDL-C: highdensity lipoprotein cholesterol; LDL-C: high-density lipoprotein cholesterol; FBG: fasting blood glucose; 2h BG: 2 hours blood glucose; SCr: serum creatinine; eGFR: estimated glomerular filtration rate; ALB: albumin; ALT: alanine aminotransferase; AST: glutamine aminotransferase; Y-GT: gamma-glutamyl transferase; HB: hemoglobin.

a $P<0.05$ compared with $\mathrm{NC}$; ${ }^{\text {b }} P<0.05$ compared with DM.

\section{The predictive accuracy of the studied markers for PTDM}

In the overall subjects, four markers including TyG-BMI, TyG, TG/HDL-C and non-HDL-C/HDL-C were compared among the NC group, PTDM group and DM group at pretransplant, 1-month posttransplant and 3-month posttransplant (Table 2). A higher TyG-BMI was found in the PTDM group and DM group than in the NC group from pretransplant to 3-month posttransplant $(P<0.01)$. TyG and non-HDL-C/HDL-C were 
markedly higher in the PTDM group and DM group at pretransplant and 3-month posttransplant $(P<0.05)$, but not at 1-month posttransplant, while no significant difference was found in the value of non-HDL-C/HDL-C among the three groups at all three timepoints.

Table 2 Comparisons of the markers in each group pretransplant and posttransplant. 


\begin{tabular}{|c|c|c|c|c|c|c|c|}
\hline Group & Marker & Time point & & & & & \\
\hline \multirow[t]{13}{*}{ Overall } & & & Total $(n=191)$ & $N C(n=145)$ & PTDM $(n=23)$ & $\mathrm{DM}(\mathrm{n}=23)$ & $P$ \\
\hline & \multirow[t]{3}{*}{ TyG-BMI } & Pretransplant & $191.32 \pm 39.44$ & $182.28 \pm 33.97$ & $214.88 \pm 30.06^{a}$ & $224.78 \pm 51.86^{a}$ & $<0.001$ \\
\hline & & $1 \mathrm{~m}$ posttransplant & $182.21 \pm 31.58$ & $176.06 \pm 28.54$ & $200.08 \pm 25.13^{a}$ & $203.09 \pm 40.14^{\mathrm{a}}$ & 0.001 \\
\hline & & $3 \mathrm{~m}$ posttransplant & $184.45 \pm 30.69$ & $178.49 \pm 28.38$ & $204.78 \pm 23.50^{a}$ & $201.91 \pm 36.09^{a}$ & $<0.001$ \\
\hline & \multirow[t]{3}{*}{ TyG } & Pretransplant & $8.85 \pm 0.77$ & $8.70 \pm 0.67$ & $9.11 \pm 0.56^{a}$ & $9.47 \pm 1.10^{a}$ & 0.010 \\
\hline & & $1 \mathrm{~m}$ posttransplant & $8.97 \pm 0.57$ & $8.88 \pm 0.48$ & $9.12 \pm 0.54$ & $9.35 \pm 0.87$ & 0.152 \\
\hline & & $3 \mathrm{~m}$ posttransplant & $9.03 \pm 0.48$ & $8.97 \pm 0.43$ & $9.22 \pm 0.36^{a}$ & $9.24 \pm 0.71^{\mathrm{a}}$ & 0.019 \\
\hline & \multirow[t]{3}{*}{ TG/HDL-C } & Pretransplant & $2.44 \pm 2.34$ & $2.15 \pm 2.00$ & $3.09 \pm 2.00$ & $3.58 \pm 3.86^{a}$ & 0.134 \\
\hline & & $1 \mathrm{~m}$ posttransplant & $1.92 \pm 1.25$ & $1.80 \pm 1.12$ & $2.17 \pm 1.45$ & $2.42 \pm 1.68$ & 0.582 \\
\hline & & $3 \mathrm{~m}$ posttransplant & $1.87 \pm 0.98$ & $1.83 \pm 0.93$ & $2.13 \pm 0.87$ & $1.86 \pm 1.31$ & 0.383 \\
\hline & \multirow[t]{3}{*}{ Non-HDL-C/HDL-C } & Pretransplant & $3.59 \pm 1.55$ & $3.44 \pm 1.53$ & $4.12 \pm 1.02^{a}$ & $3.98 \pm 1.96^{\mathrm{a}}$ & 0.029 \\
\hline & & $1 \mathrm{~m}$ posttransplant & $3.50 \pm 1.47$ & $3.35 \pm 1.41$ & $3.88 \pm 1.12$ & $4.12 \pm 1.89$ & 0.104 \\
\hline & & $3 \mathrm{~m}$ posttransplant & $3.07 \pm 1.19$ & $2.97 \pm 1.08$ & $3.67 \pm 1.12^{\mathrm{a}}$ & $3.09 \pm 1.69^{a}$ & 0.040 \\
\hline \multirow[t]{13}{*}{ FK506 } & & & Total $(n=134)$ & $N C(n=113)$ & PTDM $(n=16)$ & $\mathrm{DM}(\mathrm{n}=5)$ & $P$ \\
\hline & \multirow[t]{3}{*}{ TyG-BMI } & Pretransplant & $187.42 \pm 35.69$ & $182.74 \pm 34.27$ & $217.59 \pm 31.69^{a}$ & $196.58 \pm 36.98^{a}$ & $<0.001$ \\
\hline & & $1 \mathrm{~m}$ posttransplant & $179.90 \pm 30.15$ & $176.90 \pm 29.98$ & $202.13 \pm 25.57^{\mathrm{a}}$ & $176.47 \pm 19.19$ & 0.002 \\
\hline & & $3 \mathrm{~m}$ posttransplant & $181.88 \pm 29.51$ & $178.72 \pm 28.61$ & $209.31 \pm 24.93 \mathrm{ab}$ & $173.23 \pm 22.83$ & $<0.001$ \\
\hline & \multirow[t]{3}{*}{ TyG } & Pretransplant & $8.78 \pm 0.71$ & $8.70 \pm 0.70$ & $9.20 \pm 0.56^{a}$ & $9.20 \pm 0.81^{a}$ & 0.008 \\
\hline & & $1 \mathrm{~m}$ posttransplant & $8.97 \pm 0.52$ & $8.92 \pm 0.49$ & $9.17 \pm 0.49$ & $9.51 \pm 0.75$ & 0.061 \\
\hline & & $3 \mathrm{~m}$ posttransplant & $9.03 \pm 0.46$ & $8.98 \pm 0.44$ & $9.34 \pm 0.29$ a & $9.32 \pm 0.85^{a}$ & 0.001 \\
\hline & \multirow[t]{3}{*}{ TG/HDL-C } & Pretransplant & $2.32 \pm 2.15$ & $2.17 \pm 2.16$ & $3.37 \pm 2.09^{a}$ & $2.32 \pm 1.57^{a}$ & 0.036 \\
\hline & & $1 \mathrm{~m}$ posttransplant & $1.98 \pm 1.27$ & $1.88 \pm 1.15$ & $2.35 \pm 1.65$ & $3.15 \pm 1.92^{a}$ & 0.159 \\
\hline & & $3 \mathrm{~m}$ posttransplant & $1.93 \pm 0.96$ & $1.86 \pm 0.97$ & $2.39 \pm 0.89$ & $1.99 \pm 0.92$ & 0.054 \\
\hline & \multirow[t]{3}{*}{ Non-HDL-C/HDL-C } & Pretransplant & $3.64 \pm 1.51$ & $3.52 \pm 1.54$ & $4.26 \pm 1.05^{a}$ & $4.32 \pm 1.59$ & 0.065 \\
\hline & & $1 \mathrm{~m}$ posttransplant & $3.50 \pm 1.44$ & $3.39 \pm 1.44$ & $3.83 \pm 1.11$ & $4.88 \pm 1.79^{a}$ & 0.253 \\
\hline & & $3 \mathrm{~m}$ posttransplant & $3.06 \pm 1.11$ & $2.94 \pm 1.07$ & $3.78 \pm 0.97^{a}$ & $3.53 \pm 1.58^{a}$ & 0.007 \\
\hline \multirow[t]{8}{*}{ CsA } & & & Total $(n=57)$ & $N C(n=32)$ & PTDM $(n=7)$ & $\mathrm{DM}(\mathrm{n}=18)$ & $P$ \\
\hline & \multirow[t]{3}{*}{ TyG-BMI } & Pretransplant & $200.49 \pm 46.15$ & $180.63 \pm 33.34$ & $208.68 \pm 27.52$ & $232.61 \pm 53.47^{a}$ & 0.101 \\
\hline & & $1 \mathrm{~m}$ posttransplant & $187.64 \pm 34.37$ & $173.10 \pm 22.89$ & $195.40 \pm 25.35$ & $210.48 \pm 41.62^{a}$ & 0.178 \\
\hline & & $3 \mathrm{~m}$ posttransplant & $190.29 \pm 32.73$ & $177.70 \pm 27.97$ & $195.72 \pm 18.72$ & $209.88 \pm 35.40^{a}$ & 0.154 \\
\hline & \multirow[t]{3}{*}{ TyG } & Pretransplant & $9.00 \pm 0.88$ & $8.71 \pm 0.56$ & $8.92 \pm 0.53$ & $9.54 \pm 1.18^{a}$ & 0.762 \\
\hline & & $1 \mathrm{~m}$ posttransplant & $8.96 \pm 0.68$ & $8.76 \pm 0.42$ & $9.01 \pm 0.66$ & $9.31 \pm 0.92$ & 0.747 \\
\hline & & $3 \mathrm{~m}$ posttransplant & $9.02 \pm 0.51$ & $8.92 \pm 0.37$ & $8.98 \pm 0.39$ & $9.21 \pm 0.69$ & 0.974 \\
\hline & TG/HDL-C & Pretransplant & $2.72 \pm 2.74$ & $2.10 \pm 1.33$ & $2.43 \pm 1.74$ & $3.94 \pm 4.26^{a}$ & 0.959 \\
\hline
\end{tabular}




\begin{tabular}{|lllllll|} 
& 1m posttransplant & $1.77 \pm 1.21$ & $1.52 \pm 0.95$ & $1.75 \pm 0.81$ & $2.22 \pm 1.60$ & 0.881 \\
\cline { 2 - 7 } & 3m posttransplant & $1.72 \pm 1.00$ & $1.69 \pm 0.77$ & $1.61 \pm 0.58$ & $1.82 \pm 1.42$ & 0.984 \\
\cline { 2 - 8 } Non-HDL-C/HDL-C & Pretransplant & $3.47 \pm 1.66$ & $3.18 \pm 1.49$ & $3.78 \pm 0.93$ & $3.88 \pm 2.08$ & 0.383 \\
\cline { 2 - 8 } & 1m posttransplant & $3.51 \pm 1.53$ & $3.17 \pm 1.31$ & $3.98 \pm 1.22$ & $3.91 \pm 1.92$ & 0.206 \\
\cline { 2 - 7 } & 3m posttransplant & $3.08 \pm 1.38$ & $3.07 \pm 1.14$ & $3.43 \pm 1.45$ & $2.97 \pm 1.74$ & 0.543 \\
\hline
\end{tabular}

a $P<0.05$ compared with $N C$; ${ }^{b} P<0.05$ compared with DM.

In view of the identified correlation between FK506 usage and PTDM, a subgroup analysis according to the type of calcineurin inhibitor (CNI) was conducted. Among the patients taking FK506, a higher TyG-BMI was affirmed in the PTDM group than in the NC group $(P<0.01)$; nonetheless, no similar result was observed in the DM group. However, TyG, TG/HDL-C and non-HDL-C/HDL-C had less favorable predictive accuracy for PTDM. The TyG of the PTDM group had a higher value only at pretransplant and 3-month posttransplant, TG/HDL-C of the PTDM group had the highest value only at pretransplant, and non-HDL-C/HDL-C of the PTDM group had the highest value only at 3-month posttransplant. Conversely, in the patients taking cyclosporine (CsA), all the studied markers had no heterogeneity at any timepoint. In terms of time, from pretransplant to 3-month posttransplant, an increase in TyG was depicted in both the FK506 subgroup and CsA subgroup with a steeper slope in the FK506 subgroup, although without statistical significance (Figure 1). The changes in TyG-BMI, TG/HDL-C and nonHDL-C/HDL-C were closely analogous in the FK506 and CsA subgroups.

Among subjects with non-DM and PTDM, the values of indices were divided into three groups according to the trisection of pretransplant values, and then the incidences of PTDM were compared (Figure 2). The PTDM morbidity increased along quartiles. A high TyG-BMI at pretransplant, 1-month posttransplant and 3-month posttransplant was significantly associated with an increased risk of developing PTDM in all patients $(P<0.01)$, and a similar result was observed in the FK506 subgroup $(P<0.05)$.From the lowest TyG-BMI trisection quartile to the highest, at pretransplant, the incidence of PTDM increased from $1.79 \%$ to $26.79 \%$ in the overall patients and from $2.38 \%$ to $25.58 \%$ in the FK506 subgroup; while at 1-month posttransplant, the incidence of PTDM increased from $3.57 \%$ to $27.27 \%$ in the overall patients and from $2.33 \%$ to $26.83 \%$ in the FK506 subgroup. For TyG, when the value increased from the lowest trisection quartile to the highest, the incidence of PTDM increased from $5.08 \%$ to $20.37 \%$ at pretransplant and from $8.62 \%$ to $24.53 \%$ at 1 -month posttransplantin the overall patients.

However, in the FK506 subgroup, a favorable predictive efficacy of TyG for PTDM was determined at pretransplant and 3-month posttransplant, but not at 1-month posttransplant. In the FK506 subgroup, positive relationships were also found between TG/HDL-C and PTDM onset, because from the lowest TG/HDL-C trisection quartile to the highest, the incidence of PTDM increased from 0 to $26.83 \%$ at pretransplant and from $2.50 \%$ to $22.73 \%$ at 3-month posttransplant. A similar association was found between non-HDL-C/HDL-C and PTDM onset in the FK506 subgroup at pretransplant and 1-month posttransplant. In contrast, in the CsA subgroup, no association was verified between the studied markers and the incidence of PTDM.

\section{Correlation analysis of the markers and PTDM}

Subjects with non-DM and PTDM were the study objects of correlation analysis in our research. Direct receiver-operating characteristic (ROC) regression was implemented to further determine the discriminative power of the four markers to predict PTDM (Table 3). For the total patients, TyG-BMI at pretransplant, non-HDL-C/HDL-C at pretransplant and 1-month posttransplant had the highest sensitivity (82.61\%), while TyG at 1-month posttransplant had the highest specificity (84.14\%). In the FK506 subgroup, the highest sensitivity (100\%) and the highest NPV (100\%) were found in TyG-BMI at 3-month posttransplant, while the highest specificity (83.33\%) and the highest ACC (81.15\%) were found in non-HDL-C/HDL-C at 3-month posttransplant. In the CsA subgroup, a significant association was only shown between TyGBMI and PTDM, and TyG-BMI at 3-month posttransplant depicted the highest PPV (41.67\%). In the overall patients and FK506 subgroup, TyG-BMI, TyG, TG/HDL-C and non-HDL-C/HDL-C all showed diagnostic value for PTDM, except TG/HDL-C at 1-month posttransplant. The optimal cutoff values were 209.84 for TyG-BMI, 8.95 for TyG, 2.2 for TG/HDL-C and 3.54 for non-HDL-C/HDL-C at pretransplant in the overall subjects, the values of which were very close to that in the FK506 subgroup. Comparisons of the area under the curves (AUCs) of the four markers (Figure 3) suggested that TyG-BMI was the best diagnostic marker of PTDM in both the FK506 subgroup and CsA subgroup. In patients taking FK506, TyG at pretransplant and 3-month posttransplant, non-HDL-C/HDL-C at 3-month posttransplant can also be regarded as a good predictive factor of PTDM owing to their high AUCs (>0.7).

Table 3 Cutoff values with their corresponding sensitivity, specificity, AUC, Youden index, PPV, NPV and ACC of the markers. 


\begin{tabular}{|c|c|c|c|c|c|c|c|c|c|c|c|}
\hline & Marker & time & Cutoff & $\begin{array}{l}\text { Sensitivity } \\
(\%)\end{array}$ & $\begin{array}{l}\text { Specificity } \\
(\%)\end{array}$ & $\begin{array}{l}\text { AUC } \\
(95 \% \mathrm{Cl})\end{array}$ & $\begin{array}{l}\text { Youden } \\
\text { index }\end{array}$ & $\begin{array}{l}\text { PPV } \\
(\%)\end{array}$ & $\begin{array}{l}\text { NPV } \\
(\%)\end{array}$ & $\begin{array}{l}\text { ACC } \\
(\%)\end{array}$ & $P$ \\
\hline \multirow[t]{12}{*}{ Overall } & \multirow[t]{3}{*}{ TyG-BMI } & pretransplant & 209.84 & 65.22 & 80.00 & $\begin{array}{l}0.766 \\
(0.694- \\
0.828)\end{array}$ & 0.4522 & 34.09 & 93.55 & 77.98 & $<0.001$ \\
\hline & & $\begin{array}{l}1 \mathrm{~m} \\
\text { posttransplant }\end{array}$ & 182.73 & 82.61 & 65.52 & $\begin{array}{l}0.749 \\
(0.676- \\
0.813 \otimes\end{array}$ & 0.4813 & 27.54 & 95.96 & 67.86 & $<0.001$ \\
\hline & & $\begin{array}{l}3 \mathrm{~m} \\
\text { posttransplant }\end{array}$ & 198.09 & 71.43 & 75.54 & $\begin{array}{l}0.762 \\
(0.688- \\
0.826)\end{array}$ & 0.4697 & 30.61 & 94.59 & 75.00 & $<0.001$ \\
\hline & \multirow[t]{3}{*}{ TyG } & pretransplant & 8.95 & 60.87 & 66.90 & $\begin{array}{l}0.674 \\
(0.597- \\
0.744)\end{array}$ & 0.2777 & 22.58 & 66.90 & 36.90 & 0.002 \\
\hline & & $\begin{array}{l}1 \mathrm{~m} \\
\text { posttransplant }\end{array}$ & 9.27 & 52.17 & 84.14 & $\begin{array}{l}0.660 \\
(0.583- \\
0.731 \otimes\end{array}$ & 0.3631 & 34.29 & 91.73 & 79.76 & 0.017 \\
\hline & & $\begin{array}{l}3 \mathrm{~m} \\
\text { posttransplant }\end{array}$ & 9.06 & 71.43 & 58.99 & $\begin{array}{l}0.665 \\
(0.586- \\
0.737\end{array}$ & 0.3042 & 20.83 & 93.18 & 60.63 & 0.007 \\
\hline & \multirow[t]{3}{*}{$\begin{array}{l}\text { TG/HDL- } \\
\mathrm{C}\end{array}$} & pretransplant & 2.2 & 65.22 & 71.03 & $\begin{array}{l}0.687 \\
(0.611- \\
0.7568\end{array}$ & 0.3625 & 26.16 & 92.79 & 70.24 & $<0.001$ \\
\hline & & $\begin{array}{l}1 \mathrm{~m} \\
\text { posttransplant }\end{array}$ & 1.70 & 69.57 & 60 & $\begin{array}{l}0.621 \\
(0.543- \\
0.694)\end{array}$ & 0.2957 & 21.62 & 92.55 & 61.31 & 0.057 \\
\hline & & $\begin{array}{l}3 \mathrm{~m} \\
\text { posttransplant }\end{array}$ & 2.10 & 57.14 & 70.50 & $\begin{array}{l}0.619 \\
(0.539- \\
0.695)\end{array}$ & 0.2765 & 22.64 & 91.59 & 68.75 & 0.050 \\
\hline & \multirow[t]{3}{*}{$\begin{array}{l}\text { Non- } \\
\text { HDL- } \\
\text { C/HDL-C }\end{array}$} & pretransplant & 3.54 & 82.61 & 59.31 & $\begin{array}{l}0.658 \\
(0.581- \\
0.7298\end{array}$ & 0.4192 & 24.36 & 95.56 & 62.5 & 0.002 \\
\hline & & $\begin{array}{l}1 \mathrm{~m} \\
\text { posttransplant }\end{array}$ & 2.86 & 82.61 & 44.14 & $\begin{array}{l}0.649 \\
(0.572- \\
0.721)\end{array}$ & 0.2675 & 19.00 & 94.12 & 49.40 & 0.007 \\
\hline & & $\begin{array}{l}3 \mathrm{~m} \\
\text { posttransplant }\end{array}$ & 3.79 & 52.38 & 82.01 & $\begin{array}{l}0.689 \\
(0.611- \\
0.759)\end{array}$ & 0.3440 & 30.56 & 91.94 & 78.13 & 0.002 \\
\hline \multirow[t]{7}{*}{ FK506 } & \multirow[t]{3}{*}{ TyG-BMI } & pretransplant & 209.84 & 68.75 & 80.53 & $\begin{array}{l}0.775 \\
(0.693- \\
0.844)\end{array}$ & 0.4928 & 33.33 & 94.79 & 79.07 & $<0.001$ \\
\hline & & $\begin{array}{l}1 \mathrm{~m} \\
\text { posttransplant }\end{array}$ & 187.15 & 81.25 & 69.91 & $\begin{array}{l}0.753 \\
(0.669- \\
0.824 \rrbracket\end{array}$ & 0.5116 & 27.66 & 96.34 & 71.32 & $<0.001$ \\
\hline & & $\begin{array}{l}3 \mathrm{~m} \\
\text { posttransplant }\end{array}$ & 172.03 & 100.00 & 50.00 & $\begin{array}{l}0.794 \\
(0.711- \\
0.862)\end{array}$ & 0.5000 & 20.59 & 100 & 55.74 & $<0.0011$ \\
\hline & \multirow[t]{3}{*}{ TyG } & pretransplant & 8.75 & 81.25 & 53.10 & $\begin{array}{l}0.701 \\
(0.614- \\
0.779)\end{array}$ & 0.3435 & 19.70 & 95.24 & 56.59 & 0.001 \\
\hline & & $\begin{array}{l}1 \mathrm{~m} \\
\text { posttransplant }\end{array}$ & 9.10 & 75.00 & 64.49 & $\begin{array}{l}0.676 \\
(0.588- \\
0.7568\end{array}$ & 0.4049 & 23.53 & 94.87 & 66.67 & 0.021 \\
\hline & & $\begin{array}{l}3 \mathrm{~m} \\
\text { posttransplant }\end{array}$ & 9.14 & 85.71 & 59.26 & $\begin{array}{l}0.733 \\
(0.646- \\
0.809\end{array}$ & 0.44972 & 21.43 & 96.97 & 62.30 & $<0.001$ \\
\hline & $\begin{array}{l}\text { TG/HDL- } \\
\mathrm{C}\end{array}$ & pretransplant & 2.2 & 75.00 & 72.57 & $\begin{array}{l}0.748 \\
(0.664- \\
0.821 \otimes\end{array}$ & 0.4757 & 27.91 & 95.35 & 72.87 & $<0.001$ \\
\hline
\end{tabular}




\begin{tabular}{|c|c|c|c|c|c|c|c|c|c|c|c|}
\hline & $\begin{array}{l}1 \mathrm{~m} \\
\text { posttransplant }\end{array}$ & 2.11 & 62.50 & 70.80 & $\begin{array}{l}0.628 \\
(0.538- \\
0.711)\end{array}$ & 0.3330 & 23.26 & 93.02 & 69.77 & 0.090 \\
\hline & & $\begin{array}{l}3 \mathrm{~m} \\
\text { posttransplant }\end{array}$ & 2.07 & 71.43 & 68.52 & $\begin{array}{l}0.687 \\
(0.596- \\
0.767)\end{array}$ & 0.3995 & 22.73 & 94.87 & 68.85 & 0.003 \\
\hline & \multirow[t]{3}{*}{$\begin{array}{l}\text { Non- } \\
\text { HDL- } \\
\text { C/HDL-C }\end{array}$} & pretransplant & 3.64 & 87.50 & 61.06 & $\begin{array}{l}0.678 \\
0.590- \\
0.757 \rrbracket\end{array}$ & 0.4856 & 24.14 & 97.18 & 64.34 & 0.003 \\
\hline & & $\begin{array}{l}1 \mathrm{~m} \\
\text { posttransplant }\end{array}$ & 2.93 & 81.25 & 45.13 & $\begin{array}{l}0.632 \\
(0.542- \\
0.715)\end{array}$ & 0.2638 & 17.33 & 94.44 & 49.61 & 0.047 \\
\hline & & $\begin{array}{l}3 \mathrm{~m} \\
\text { posttransplant }\end{array}$ & 3.78 & 64.29 & 83.33 & $\begin{array}{l}0.735 \\
(0.648- \\
0.811)\end{array}$ & 0.3440 & 33.33 & 94.74 & 81.15 & $<0.001$ \\
\hline \multirow[t]{12}{*}{ CsA } & \multirow[t]{3}{*}{ TyG-BMI } & pretransplant & 180.23 & 85.71 & 59.38 & $\begin{array}{l}0.754 \\
(0.591- \\
0.878)\end{array}$ & 0.4509 & 31.58 & 95.00 & 64.10 & 0.006 \\
\hline & & $\begin{array}{l}1 \mathrm{~m} \\
\text { posttransplant }\end{array}$ & 182.69 & 85.71 & 68.75 & $\begin{array}{l}0.768 \\
0.605- \\
0.888 \rrbracket\end{array}$ & 0.5446 & 37.50 & 95.65 & 71.79 & 0.031 \\
\hline & & $\begin{array}{l}3 \mathrm{~m} \\
\text { posttransplant }\end{array}$ & 195.49 & 71.43 & 77.42 & $\begin{array}{l}0.700 \\
(0.530- \\
0.838)\end{array}$ & 0.4885 & 41.67 & 92.31 & 76.32 & 0.042 \\
\hline & \multirow[t]{3}{*}{ TyG } & pretransplant & 9.23 & 42.86 & 81.25 & $\begin{array}{l}0.589 \\
(0.421- \\
0.744)\end{array}$ & 0.2411 & 33.33 & 86.67 & 74.36 & 0.483 \\
\hline & & $\begin{array}{l}1 \mathrm{~m} \\
\text { posttransplant }\end{array}$ & 9.24 & 42.86 & 93.75 & $\begin{array}{l}0.650 \\
(0.480- \\
0.795 \rrbracket\end{array}$ & 0.3661 & 60.00 & 88.24 & 84.62 & 0.277 \\
\hline & & $\begin{array}{l}3 \mathrm{~m} \\
\text { posttransplant }\end{array}$ & 8.58 & 100.00 & 22.58 & $\begin{array}{l}0.525 \\
(0.357- \\
0.689\end{array}$ & 0.2258 & 22.58 & 100 & 36.84 & 0.847 \\
\hline & \multirow[t]{3}{*}{$\begin{array}{l}\text { TG/HDL- } \\
\mathrm{C}\end{array}$} & pretransplant & 3.70 & 28.57 & 93.75 & $\begin{array}{l}0.545 \\
0.378- \\
0.705 \rrbracket\end{array}$ & 0.2232 & 50.00 & 85.71 & 82.05 & 0.736 \\
\hline & & $\begin{array}{l}1 \mathrm{~m} \\
\text { posttransplant }\end{array}$ & 1.27 & 85.71 & 59.38 & $\begin{array}{l}0.652 \\
(0.483- \\
0.797)\end{array}$ & 0.4509 & 31.58 & 95.00 & 64.10 & 0.236 \\
\hline & & $\begin{array}{l}3 \mathrm{~m} \\
\text { posttransplant }\end{array}$ & 1.45 & 71.43 & 48.39 & $\begin{array}{l}0.507 \\
(0.340- \\
0.673)\end{array}$ & 0.1982 & 23.81 & 88.24 & 52.63 & 0.957 \\
\hline & \multirow[t]{3}{*}{$\begin{array}{l}\text { Non- } \\
\text { HDL- } \\
\text { C/HDL-C }\end{array}$} & pretransplant & 2.55 & 100.00 & 34.38 & $\begin{array}{l}0.625 \\
(0.456- \\
0.775 \square\end{array}$ & 0.3438 & 25.00 & 100 & 46.15 & 0.207 \\
\hline & & $\begin{array}{l}1 \mathrm{~m} \\
\text { posttransplant }\end{array}$ & 3.5 & 71.43 & 68.75 & $\begin{array}{l}0.705 \\
(0.538- \\
0.840)\end{array}$ & 0.4018 & 33.33 & 91.67 & 69.23 & 0.046 \\
\hline & & $\begin{array}{l}3 m \\
\text { posttransplant }\end{array}$ & 2.63 & 85.71 & 41.94 & $\begin{array}{l}0.571 \\
(0.401- \\
0.730)\end{array}$ & 0.2765 & 25.00 & 92.86 & 50.00 & 0.567 \\
\hline
\end{tabular}

PPV, positive predictive value; NPV, negative predictive value; ACC: accuracy rate.

Logistic regression analysis using trisector 1 as a reference group affirmed that the ORs of PTDM increased nonlinearly along with the trisectors of the four markers at pretransplant (Table 4). Specifically, at pretransplant, in the initial crude analysis (Model 1), the risk of PTDM was 20.89 times higher in subjects with the highest trisector TyG-BMI (95\% Cl: 14.95-29.20), 6.70 times higher in subjects in the highest trisector of TyG (95\% Cl: 5.25-8.54), 10.46 times higher in subjects in the highest trisector of TG/HDL-C (95\% Cl: 8.11-13.48), and 4.28 times higher in subjects in the highest trisector of non-HDL-C/HDL-C (95\% Cl: 3.51-5.21). The association between the studied markers and the 
incidence of PTDM remained significant after multivariate adjustment. After adjusting for smoking, drinking, BMI and HCV (Model 2), the highest ORs were obtained in the highest trisector of TyG-BMI (5.44, 95\% Cl:3.27-9.07), in the highest trisector of TyG (3.22, 95\% Cl: 2.474.20), in the highest trisector of TG/HDL-C (4.97, 95\% Cl: 3.76-6.56), and in the second trisector of non-HDL-C/HDL-C (2.25, 95\%Cl: 1.78-2.84). After adjusting for CNIs, TC, LDL-C, ALB, ALT, eGFR and $\mathrm{Hb}$ based on Model 2 (Model 3), significantly high ORs were still observed with a value of 3.25 (95\% Cl: $2.01-5.27)$ in the second trisector of TyG-BMI, 6.25 (95\% Cl: 4.30-9.09) in the highest trisector of TyG, 7.29 (95\% Cl: $4.91-$ $10.83)$ in the highest trisector of TG/HDL-C, and 6.95 (95\% Cl: 4.37-11.04) in the highest trisector of non-HDL-C/HDL-C. The relationships between the studied markers and PTDM were still definite at 1-month and 3-month posttransplant regardless of whether the interference factors had been adjusted. After transplantation, the largest ORs of TyG-BMI and non-HDL-C/HDL-C were found at 1-month posttransplant, while the largest ORs of TyG and TG/HDL-C were found at 3-month posttransplant. At the early-stage posttransplant, the four studied markers had all been approved as independent predictors for PTDM.

Table 4 Odds ratios and 95\% confidence intervals of the markers and incident PTDM $(\mathrm{N}=191)$ 


\begin{tabular}{|c|c|c|c|c|c|c|c|c|}
\hline \multicolumn{3}{|l|}{ time } & \multirow{2}{*}{$\begin{array}{l}\text { Model } 1 \\
1 \text { (References) }\end{array}$} & \multirow[t]{2}{*}{$\begin{array}{l}\mathrm{P} \\
\text { Value }\end{array}$} & \multirow{2}{*}{$\begin{array}{l}\text { Model } 2 \\
1 \text { (References) }\end{array}$} & \multirow[t]{2}{*}{$\begin{array}{l}\mathrm{P} \\
\text { Value }\end{array}$} & \multirow{2}{*}{$\begin{array}{l}\text { Model } 3 \\
1 \\
\text { (References) }\end{array}$} & \multirow[t]{2}{*}{$\begin{array}{l}\mathrm{P} \\
\text { Value }\end{array}$} \\
\hline pretransplant & TyG-BMI index & T1 $(<168.05)$ & & & & & & \\
\hline & & $\begin{array}{l}\text { T2 (168.05- } \\
199.37)\end{array}$ & $\begin{array}{l}8.26(5.84- \\
11.68)\end{array}$ & $<0.001$ & $\begin{array}{l}5.32(3.36- \\
8.41)\end{array}$ & $<0.001$ & $\begin{array}{l}3.25(2.01- \\
5.27)\end{array}$ & $<0.001$ \\
\hline & & T3 (囚199.37) & $\begin{array}{l}20.89 \text { (14.95- } \\
29.20)\end{array}$ & $<0.001$ & $\begin{array}{l}5.44(3.27- \\
9.07)\end{array}$ & $<0.001$ & $\begin{array}{l}2.02(1.07- \\
3.81)\end{array}$ & 0.030 \\
\hline & & $P$ for trend & $<0.001$ & & $<0.001$ & & $<0.001$ & \\
\hline & TyG index & $\mathrm{T} 1(<8.55)$ & 1 (References) & & 1 (References) & & $\begin{array}{l}1 \\
\text { (References) }\end{array}$ & \\
\hline & & $\begin{array}{l}\text { T2 (8.55- } \\
9.05)\end{array}$ & $\begin{array}{l}4.69(3.66- \\
6.00)\end{array}$ & $<0.001$ & $\begin{array}{l}2.89(2.21- \\
3.78)\end{array}$ & $<0.001$ & $\begin{array}{l}3.58(2.48- \\
5.17)\end{array}$ & $<0.001$ \\
\hline & & T3 (『9.05) & $\begin{array}{l}6.70(5.25- \\
8.54)\end{array}$ & $<0.001$ & $\begin{array}{l}3.22(2.47- \\
4.20)\end{array}$ & $<0.001$ & $\begin{array}{l}6.25(4.30- \\
9.09)\end{array}$ & $<0.001$ \\
\hline & & $P$ for trend & $<0.001$ & & $<0.001$ & & $<0.001$ & \\
\hline & TG/HDL-C ratio & $\mathrm{T} 1(<1.31)$ & 1 (References) & & 1 (References) & & $\begin{array}{l}1 \\
\text { (References) }\end{array}$ & \\
\hline & & $\begin{array}{l}\text { T2 (1.31- } \\
2.26)\end{array}$ & $\begin{array}{l}3.79(2.89- \\
4.97)\end{array}$ & $<0.001$ & $\begin{array}{l}2.69(2.01- \\
3.59)\end{array}$ & $<0.001$ & $\begin{array}{l}3.35(2.23- \\
5.04)\end{array}$ & $<0.001$ \\
\hline & & T3 (『2.26) & $\begin{array}{l}10.46(8.11- \\
13.48)\end{array}$ & $<0.001$ & $\begin{array}{l}4.97(3.76- \\
6.56)\end{array}$ & $<0.001$ & $\begin{array}{l}7.29(4.91- \\
10.83)\end{array}$ & $<0.001$ \\
\hline & & $P$ for trend & $<0.001$ & & $<0.001$ & & $<0.001$ & \\
\hline & $\begin{array}{l}\text { non-HDL-C/HDL- } \\
\text { C ratio }\end{array}$ & $\mathrm{T} 1(<2.77)$ & 1 (References) & & 1 (References) & & $\begin{array}{l}1 \\
\text { (References) }\end{array}$ & \\
\hline & & $\begin{array}{l}\text { T2 (2.77- } \\
4.06)\end{array}$ & $\begin{array}{l}1.96(1.59- \\
2.43)\end{array}$ & $<0.001$ & $\begin{array}{l}2.25(1.78- \\
2.84)\end{array}$ & $<0.001$ & $\begin{array}{l}3.29(2.16- \\
5.03)\end{array}$ & $<0.001$ \\
\hline & & T3 (『4.06) & $\begin{array}{l}4.28(3.51- \\
5.21)\end{array}$ & $<0.001$ & $\begin{array}{l}1.71(1.35- \\
2.15)\end{array}$ & $<0.001$ & $\begin{array}{l}6.95(4.37- \\
11.04)\end{array}$ & $<0.001$ \\
\hline & & $P$ for trend & $<0.001$ & & $<0.001$ & & $<0.001$ & \\
\hline $\begin{array}{l}1 \mathrm{~m} \\
\text { posttransplant }\end{array}$ & TyG-BMI index & $\mathrm{T} 1(<161.34)$ & 1 (References) & & 1 (References) & & $\begin{array}{l}1 \\
\text { (References) }\end{array}$ & \\
\hline & & $\begin{array}{l}\text { T2 (161.34- } \\
189.94)\end{array}$ & $\begin{array}{l}3.90(2.94- \\
5.18)\end{array}$ & $<0.001$ & $\begin{array}{l}4.90(3.56- \\
6.73)\end{array}$ & $<0.001$ & $\begin{array}{l}3.00(1.75- \\
5.15)\end{array}$ & $<0.001$ \\
\hline & & T3 (囚189.94) & $\begin{array}{l}15.42(11.78- \\
20.19)\end{array}$ & $<0.001$ & $\begin{array}{l}18.37(12.34- \\
27.33)\end{array}$ & $<0.001$ & $\begin{array}{l}2.55(1.41- \\
4.62)\end{array}$ & 0.002 \\
\hline & & $P$ for trend & $<0.001$ & & $<0.001$ & & $<0.001$ & \\
\hline & TyG index & T1 $(<8.73)$ & 1 (References) & & 1 (References) & & $\begin{array}{l}1 \\
\text { (References) }\end{array}$ & \\
\hline & & $\begin{array}{l}\text { T2 (8.73- } \\
9.16)\end{array}$ & $\begin{array}{l}1.28(1.03- \\
1.59)\end{array}$ & 0.024 & $\begin{array}{l}1.42(1.14- \\
1.78)\end{array}$ & 0.002 & $\begin{array}{l}1.64(1.19- \\
2.26)\end{array}$ & 0.002 \\
\hline & & T3 (『9.16) & $\begin{array}{l}4.85(4.02- \\
5.86)\end{array}$ & $<0.001$ & $\begin{array}{l}6.14(4.98- \\
7.58)\end{array}$ & $<0.001$ & $\begin{array}{l}14.41(9.94- \\
20.89)\end{array}$ & $<0.001$ \\
\hline & & $P$ for trend & $<0.001$ & & $<0.001$ & & $<0.001$ & \\
\hline & TG/HDL-C ratio & $\mathrm{T} 1(<1.25)$ & 1 (References) & & 1 (References) & & $\begin{array}{l}1 \\
\text { (References) }\end{array}$ & \\
\hline & & $\begin{array}{l}\text { T2 (1.25- } \\
2.03)\end{array}$ & $\begin{array}{l}3.89(3.07- \\
4.92)\end{array}$ & $<0.001$ & $\begin{array}{l}4.79(3.73- \\
6.14)\end{array}$ & $<0.001$ & $\begin{array}{l}7.60(5.02- \\
11.49)\end{array}$ & 0.005 \\
\hline & & T3 (『2.03) & $\begin{array}{l}9.24(7.32- \\
11.65)\end{array}$ & $<0.001$ & $\begin{array}{l}7.70(6.06- \\
9.79)\end{array}$ & $<0.001$ & $\begin{array}{l}16.07(10.82- \\
23.87)\end{array}$ & $<0.001$ \\
\hline
\end{tabular}

Page $11 / 18$ 


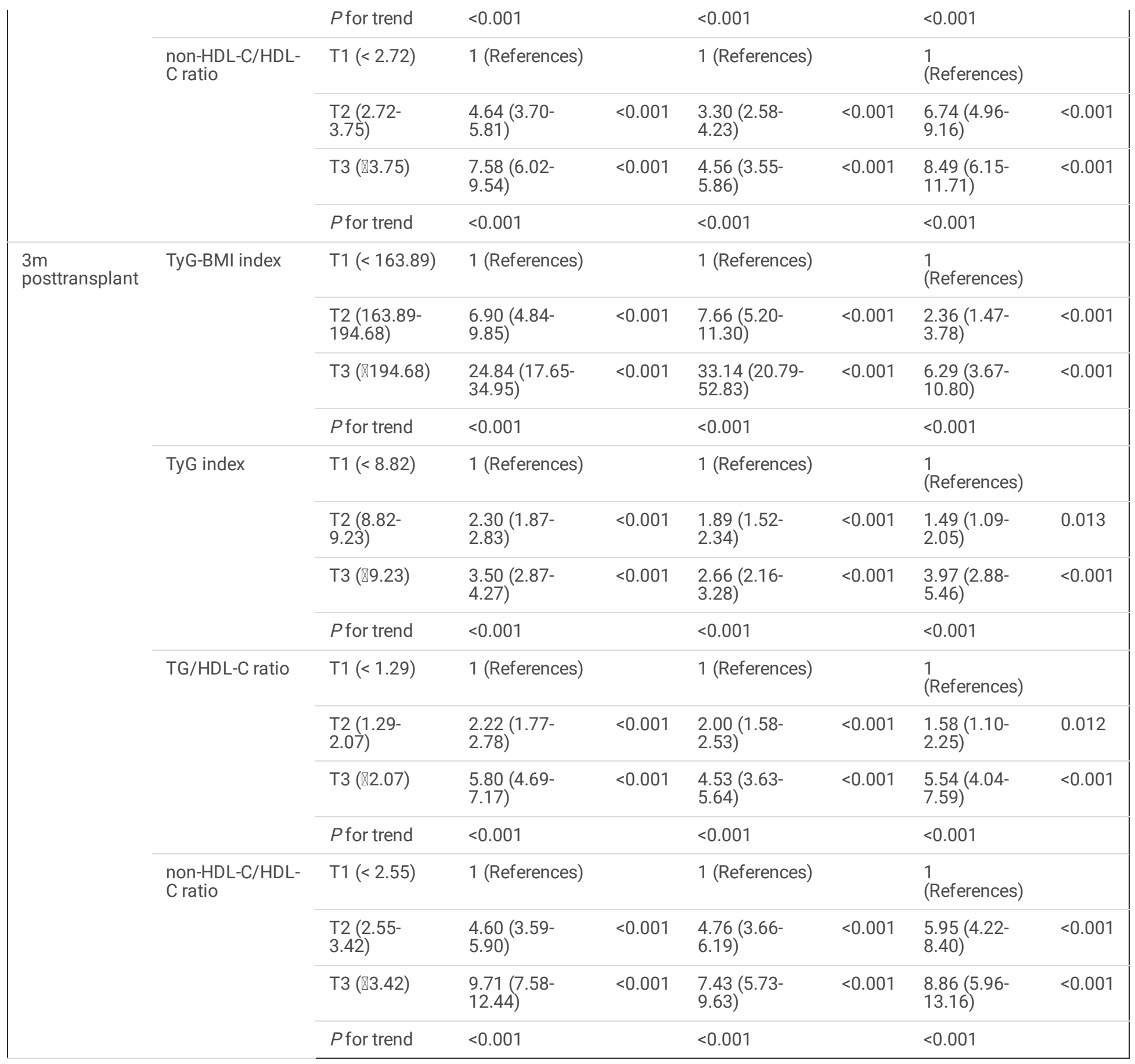

Model 1: adjusted for sex and age; Model 2: adjusted for sex, age, smoking, drinking, obesity, hypertension and viral hepatitis C; Model 3: Model 2 and further adjusted for CNIs, total cholesterol, low-density lipoprotein cholesterol, albumin, alanine aminotransferase, estimated glomerular filtration rate and hemoglobin.

\section{Discussion}

PTDM is a noteworthy complication of renal transplantation. In our study we observed that $12.04 \%$ of RT recipients developed PTDM, and significantly higher values of TyG-BMI, TyG and non-HDL-C/HDL-C was found in patients with PTDM than in nondiabetic patients, especially among the recipients taking FK506 at pretransplant. The incidence of PTDM increased along with the values of TyG or TyG-BMI. After adjusting for multiple potential factors, recipients with the highest quartile of TyG or TyG-BMI still had a higher risk of PTDM morbidity than those with the lowest quartile, suggesting the potential for TyG and TyG-BMI to serve as independent risk indicators of PTDM in clinical practice.

IR may induce glomerular and vascular hemodynamic changes because compensatory hyperinsulinemia can lead to dysfunctional tubuloglomerular feedback caused by an increase in sodium absorption at the proximal tubules and in the loop of Henle, stimulating 
mesangial cell proliferation and mesangial matrix production [13]. Posttransplant IR has been associated with subclinical atheromasia and chronic subclinical inflammation. Therefore, IR after RT remains prevalent and important, and is an early and very strong predictor of graft function and survival, CV disease and metabolic complications, including PTDM.

Recently, TyG-related indices were introduced as easily measurable, economical and applicable surrogate markers of IR instead of the hyperinsulinemic-euglycemic clamp test and HOMA-IR index [7,14]. The TyG proposed by Guerrero-Romero has shown high sensitivity and specificity in the measurement of IR, metabolic abnormalities, T2DM onset and T2DM-related complication risk [7,15-17]; moreover, it was revealed to be a more efficient marker for the early identification of IR than lipid ratios, VAI and LAP in a cross-sectional study [18]. In the diabetic patients with poor glycemic control, TyG increased significantly and was significantly correlated with HbA1c [19]. The results of several population-based studies have demonstrated that TyG was positively associated with fat distribution, subclinical atherosclerosis, coronary artery disease, prehypertension, hyperuricemia and nonalcoholic fatty liver disease [20-22].

The application of TyG-related indices was based on the fact that both lipotoxicity and glucotoxicity play crucial roles in IR modulation. Accumulating evidence suggests close relationships between IR, obesity and hyperlipoidemia in both diabetic and nondiabetic subjects [11]. One integrative physiological research proposed that hypertriglyceridemia had a negative effect on IR, because it might cause fatty acid accumulation in non-adipose tissues such as the liver, muscle and heart, resulting in ectopic lipid deposition with lipotoxicity [23]. Elevated TG, LDL-C and low HDL-C are probably detected secondary to IR and hyperinsulinism, but before the onset of prediabetes [24]. For RT recipients, preceding studies proposed that the presence of obesity and hyperlipoidemia increases the risks of PTDM and long-term patient and graft loss [25].

Several literatures have reported that TyG-BMI, a combination of the TyG and BMI, is the most favorable surrogate marker of IR [26]. Lim et al. and Er et al. concluded that TyG-BMI was superior to TyG, TyG-WC (waist circumference) and TyG-WHtR (waist-to-height ratio) for IR prediction, with a higher OR and the largest AUC of 0.748 in all subjects [27], regardless of the sex [26]. We obtained similar results, reaffirming that TyG-BMI had a larger AUC than TyG, TG/HDL-C and non-HLD-C/HDL-C from pretransplant to 3-month posttransplant, regardless of the type of CNI. The highest TyG-BMI AUC of 0.775 was found in recipients taking FK506 with the optimal cutoff point of 209.84 at pretransplant. A cross-sectional study in Taiwanese individuals also affirmed that TyG-BMI was the most favorable surrogate marker of IR, and TyG-BMI had the strongest association with HOMA-IR ${ }^{[26]}$. In nondiabetic Chinese subjects, TyG-BMI was a better indicator for detecting IR in both the normal glucose and all glucose categories subjects [28]. In Colombian men, TyG-BMI also had higher OR and AUC values in prediabetes patients than in the nondiabetic population [29]. It is noteworthy that in the current investigation, the values of TyG increased early after transplantation among the recipients taking FK506, but the values of TyG-BMI decreased. Malnutrition and acceleration of metabolism maybe the reasons for these changes, which were caused by surgical operations and the usage of prednisone respectively. The nutritional assessment of patients verified inadequate body composition, with increased fat and reduced lean body mass early after renal transplantation [30]. Therefore, it is not recommended to predict PTDM using the dynamic changes in TyG-BMI from pretransplant to early posttransplant.

Lipid parameters such as TG/HDL-C and non-HDL-C/HDL-C are additional markers of IR that have been suggested by some researchers. Hyperinsulinemia was positively associated with the serum TG concentration [31] and inversely associated with the serum HDL-C concentration; moreover, the concentrations of TG and HDL-C might be influenced by glycemic control in patients with diabetes [32]. Furthermore, low HDL-C concentrations may exacerbate abnormal glucose homeostasis [33]. For RT recipients in our study, although the associations between TG/HDL-C, non-HDL-C/HDL-C and the incidence of PTDM were significant even after adjusting for various factors, the significant relationships were not maintained when compared according to the trisectors of the values. Obvious predictive abilities were particularly found for TG/HDL-C at pretransplant and non-HDL-C/HDL-C at 3-month posttransplant only among recipients taking FK506. Among recipients taking FK506, high AUCs were obtained at pretransplant and 3-month posttransplant both for TG/HDL-C and non-HDL$\mathrm{C} / \mathrm{HDL}-\mathrm{C}$, while among recipients taking $\mathrm{CsA}$, a high AUC was obtained only at 1-month posttransplant for non-HDL-C/HDL-C. Our results were partly in concordance with previous findings that TG/HDL-C is a practical approach for identifying individuals with diabetes [34]. In the Bypass Angioplasty Revascularization Investigation 2 Diabetes trial, TG/HDL-C was proposed to be a useful marker in individuals who achieved better glycemic control [35], and another study found that TG/HDL-C can be an effective screening tool to predict success with dose reductions of antidiabetic medications in obese patients who successfully lose weight [36]. TG/HDL-C can also be a pretransplant index of IR to predict both PTDM and glucose intolerance after transplantation [37,38]. Among all lipid parameters, it was reported by several articles that TG/HDL-C was more efficient than any other lipid measures or ratios in terms of the strength of the association with IR [26]. We found that a TG/HDL-C value above 2.2 was a better marker of PTDM in the FK506 subgroup, while McLaughlin et al. [39] found that a TG/HDL-C value above $3.0 \mathrm{mg} / \mathrm{dL}$ was a better marker of IR, indicating that TG/HDL-C can be a more sensitive marker in RT recipients than in the general population. Non-HDL-C/HDL-C has also been suggested as a better predictor of CVD than LDL-C, non-HDL-C, apolipoprotein B or apolipoprotein A1 [40], however, its predictive value for PTDM has not been studied extensively, so our data can be a valuable reference in this regard in future research. 
We further conducted stratified analyses to investigate whether the type of CNIs affected the association between the studied markers and PTDM. High values of TyG, TyG-BMI, TG/HDL-C and non-HDL-C/HDL-C were significantly associated with PTDM only in the FK506 subgroup, but not in the CsA subgroup. The AUCs of the markers above were all higher in the FK506 subgroup than in the CsA subgroup, and among the four markers, only TyG-BMI had a statistically significant predictive value for PTDM in the CsA subgroup. This finding was consistent with previous studies, among which Esteban et al. observed that the combination of FK506 plus pretransplant hypertriglyceridemia was a risk factor for PTDM, highlighting the importance of FK506 in the pathogenesis of PTDM [37]. Nevertheless, there was no obvious difference in the values of the four markers between the FK506 subgroup and CsA subgroup, indicating that the etiology of PTDM involved many elements and not just the type of CNI.

Our study still had several limitations that need to be considered. First, it was a retrospective study with a relatively small sample size, so confounding factors cannot be controlled well. There are few similar studies focusing on RT recipients, which may limit possible comparisons. Second, the HOMA-IR index was not calculated, so direct comparisons between the indices and the HOMA-IR index were missing in this study. Additionally, we did not analyze WC or WHtR. Measurement accuracy was a main limitation of WC or WHtR application [41], and interobserver variabilities of WC may range from $86 \%$ to $99 \%$ [42]. The interobserver variabilities of circumferences observed for WC were higher than those of BMI [43]. Moreover, WC alone cannot fully represent visceral adipose tissues due to its poor differentiation between subcutaneous and visceral adipose tissues [44]. That is, the advantages of obesity indices remain controversial, and further additional research is required. Third, our study cohort mostly comprised the South Zhejiang population in China which is not nationally representative and lacks geographical diversity. Therefore, further prospective and exhaustive studies are necessary to confirm the results we found.

\section{Conclusions}

In conclusion, predicted insulin resistance and its related metabolic risk factors play an essential role in the development of PTDM. TyG, TyG$\mathrm{BMI}, \mathrm{TG} / \mathrm{HDL}-\mathrm{C}$ and non-HDL-C/HDL-C were significantly associated with a higher incidence of PTDM in RT recipients, and TyG-BMI was the best alternative marker among the four markers for early identification of PTDM. In routine management of renal transplantation, TyG and TyG-BMI can be used as cost-effective and complementary monitors to identify individuals at high risk of PTDM.

\section{Declarations}

\section{Data Availability}

All data generated or analyzed during this study are included in this published article and its supplementary information file.

\section{Author contributions}

BC.C. participated in study design and coordination, made contributions to acquisition of data and helped to write the manuscript. XJ.N. participated in design of the study, performed the statistical analysis and interpretation and wrote the manuscript. YL.L., TT.H. and Y.Z. participated in the analysis and the acquisition of data and discussion. All authors contributed to discussion and critically reviewed and revised the manuscript. BC.C. is the guarantor of this work and takes responsibility for the integrity of the data and the accuracy of the data analysis.

\section{Competing Interests}

The authors declare no competing interests.

\section{References}

1. Sheu, A., Depczynski, B., O'Sullivan, A.J., Luxton, G. \& Mangos, G. The effect of different glycaemic states on renal transplant outcomes. Diabetes Res. 2016,8735782; 10.1155/2016/8735782 (2016).

2. Burroughs, T.E. et al. Diabetic complications associated with new-onset diabetes mellitus in renal transplant recipients. 83, 1027-1034 (2007).

3. Cron, D.C. et al. Using analytic morphomics to describe body composition associated with post-kidney transplantation diabetes mellitus. Transplant. 31; 10.1111/ctr.13040 (2017).

4. Ekstrand, A.V., Eriksson, J.G., Gronhagen-Riska, C., Ahonen, P.J. \& Groop, L.C. Insulin resistance and insulin deficiency in the pathogenesis of posttransplantation diabetes in man. 53, 563-569 (1992).

5. Liang, S., Cai, G.Y. \& Chen, X.M. Clinical and pathological factors associated with progression of diabetic nephropathy. Nephrology (Carlton). 22, 14-19 (2017). 
6. DeFronzo, R.A., Tobin, J.D. \& Andres, R. Glucose clamp technique: a method for quantifying insulin secretion and resistance. J. Physiol. 237, E214-223 (1979).

7. Guerrero-Romero, F. et al. The product of triglycerides and glucose, a simple measure of insulin sensitivity. Comparison with the euglycemic-hyperinsulinemic clamp. Clin. Endocrinol Metab. 95, 3347-3351 (2010).

8. Unger, G., Benozzi, S.F., Perruzza, F. \& Pennacchiotti, G.L. Triglycerides and glucose index: a useful indicator of insulin resistance. Endocrinol Nutr. 61, 533-540 (2014).

9. Li, Z. et al. Alcohol consumption and cardiovascular diseases in rural China. J. Cardiol. 215, 257-262 (2016).

10. Sánchez-Íñigo. L., Navarro-González, D., Fernández-Montero, A., Pastrana-Delgado, J. \& Martínez, JA. The TyG index may predict the development of cardiovascular events. J. Clin. Invest. 46, 189-197 (2016).

11. Finucane, F.M. et al. Correlation of the leptin: adiponectin ratio with measures of insulin resistance in non- diabetic individuals. 52, 23452349 (2009).

12. American Diabetes Association. Improving Care and Promoting Health in Populations: Standards of Medical Care in Diabetes-2020. Diabetes Care. 43,S7-S13 (2020).

13. Sarafidis, P.A. \& Ruilope, L.M. Insulin resistance, hyperinsulinemia, and renal injury: mechanisms and implications. J. Nephrol. 26, 232244 (2006).

14. Abbasi, F. \& Reaven, G.M. Comparison of two methods using plasma triglyceride concentration as a surrogate estimate of insulin action in nondiabetic subjects: triglycerides_glucose versus triglyceride/highdensity lipoprotein cholesterol. Metabolism. 60, 1673-1676 (2011).

15. Abbasi, F. \& Reaven, G,M. Comparison of two methods using plasma triglyceride concentration as a surrogate estimate of insulin action in nondiabetic subjects: triglycerides $\times$ glucose versus triglyceride/high-density lipoprotein cholesterol. 60, 1673-1676 (2011).

16. Yu, X. et al. Fasting triglycerides and glucose index is more suitable for the identification of metabolically unhealthy individuals in the Chinese adult population: A nationwide study. Diabetes Investig. 10, 1050-1058 (2019).

17. Jin, J.L. et al. Triglyceride glucose and haemoglobin glycation index for predicting outcomes in diabetes patients with new-onset, stable coronary artery disease: a nested case-control study. Med. 50, 576-586 (2018).

18. Du, T. et al. Clinical usefulness of lipid ratios, visceral adiposity indicators, and the triglycerides and glucose index as risk markers of insulin resistance. Diabetol. 13, 146 (2014).

19. Hameed, E,K. TyG index a promising biomarker for glycemic control in type 2 Diabetes Mellitus. Diabetes Metab. Syndr. 13, 560-563 (1029).

20. Liu, X.Z., Xu, X., Zhu, J.Q. \& Zhao, D.B. Association between three non-insulin-based indexes of insulin resistance and hyperuricemia. Rheumatol. 38, 3227-3233 (2019).

21. Su, W.Y. et al. Comparison of the Effects of Fasting Glucose, Hemoglobin A1c, and Triglyceride-Glucose Index on Cardiovascular Events in Type 2 Diabetes Mellitus. 11, 2838 (2019).

22. Zhang, S. et al. The triglyceride and glucose index (TyG) is an effective biomarker to identify nonalcoholic fatty liver disease. Lipids Health Dis. 16, 15 (2017).

23. Bickerton, A.S. et al. Preferential uptake of dietary Fatty acids in adipose tissue and muscle in the postprandial period. 56, $168-176$ (2007).

24. Delgado, P. et al. Unmasking glucose metabolism alterations in stable renal transplant recipients: a multicenter study. J. Am. Soc. Nephrol. 3, 808-813 (2008).

25. Chang, S. \& Jiang, J. Association of Body Mass Index and the Risk of New-Onset Diabetes After Kidney Transplantation: A Metaanalysis. Transplant Proc. 50, 1316-1325 (2018).

26. Er, L.K. et al. Triglyceride Glucose-Body Mass Index Is a Simple and Clinically Useful Surrogate Marker for Insulin Resistance in Nondiabetic Individuals. PLoS One. 11, e0149731 (2016).

27. Lim, J., Kim, J., Koo, S.H. \& Kwon, G.C. Comparison of triglyceride glucose index, and related parameters to predict insulin resistance in Korean adults: An analysis of the 2007-2010 Korean National Health and Nutrition Examination Survey. PLoS One. 14, e0212963 (2019).

28. Tuo, X., Yuan, J., Wang, X.H. \& Xin, Z. Identifying the insulin resistance index in nondiabetic Chinese subjects. Medicine (Baltimore). 99, e19023 (2020).

29. Ramírez-Vélez, R. et al. Obesity- and Lipid-Related Parameters in the Identification of Older Adults with a High Risk of Prediabetes According to the American Diabetes Association: An Analysis of the 2015 Health, Well-Being, and Aging Study. 11, 2654 (2019).

30. Netto, M.C., Alves-Filho, G. \& Mazzali, M. Nutritional status and body composition in patients early after renal transplantation. Transplant Proc. 44, 2366-2368 (2012).

Page 15/18 
31. Stalder, M., Pometta, D. \& Suenram, A. Relationship between plasma insulin levels and high density lipoprotein cholesterol levels in healthy men. 21, 544-548 (1981).

32. Quispe, R., Martin, S.S. \& Jones, S.R. Triglycerides to high-density lipoprotein-cholesterol ratio, glycemic control and cardiovascular risk in obese patients with type 2 diabetes. Opin. Endocrinol Diabetes Obes. 23, 150-156 (2016).

33. Drew, B.G., Rye, K.A., Duffy, S.J., Barter, P. \& Kingwell, B.A. The emerging role of HDL in glucose metabolism. Rev. Endocrinol. 8, 237-245 (2012).

34. González-Chávez, A., Simental-Mendía, L.E. \& Elizondo-Argueta, S. Elevated triglycerides/HDL-cholesterol ratio associated with insulin resistance. Cir. 79, 126-131 (2011).

35. Zonszein, J. et al. Triglyceride High-Density Lipoprotein Ratios Predict Glycemia-Lowering in Response to Insulin Sensitizing Drugs in Type 2 Diabetes: A Post Hoc Analysis of the BARI 2D. Diabetes Res. 2015, 129891 (2015).

36. Palamaner Subash Shantha, G., Kumar, A.A., Kahan, S., Irukulla, P.K. \& Cheskin, L.J. Triglyceride/HDL ratio as a screening tool for predicting success at reducing anti-diabetic medications following weight loss. PLoS One. 8, e69285 (2018).

37. Porrini, E. et al. The combined effect of pre-transplant triglyceride levels and the type of calcineurin inhibitor in predicting the risk of new onset diabetes after renal transplantation. Dial. Transplant. 23, 1436-1441 (2008).

38. Porrini, E. et al. Prediabetes in patients receiving tacrolimus in the first year after kidney transplantation: a prospective and multicenter study. 85, 1133-1138 (2008).

39. McLaughlin, T. et al. Use of metabolic markers to identify overweight individuals who are insulin resistant. Intern. Med. 139, 802-809 (2003).

40. Lamprea-Montealegre, J.A. et al. Chronic kidney disease, lipids and apolipoproteins, and coronary heart disease: the ARIC study. 234, 4246 (2014).

41. Wang, J. et al. Comparisons of waist circumferences measured at 4 sites. J. Clin. Nutr. 77, 379-384 (2003).

42. Ulijaszek, S.J. \& Kerr, D.A. Anthropometric measurement error and the assessment of nutritional status. J. Nutr. 82, 165-177 (1999).

43. Nádas, J., Putz, Z., Kolev, G., Nagy, S. \& Jermendy, G. Intraobserver and interobserver variability of measuring waist circumference. Sci. Monit. 14, CR15-18 (2008).

44. Zheng, S. et al. Triglyceride glucose-waist circumference, a novel and effective predictor of diabetes in first-degree relatives of type 2 diabetes patients: cross-sectional and prospective cohort study. J. Transl. Med. 14, 260 (2016).

\section{Figures}

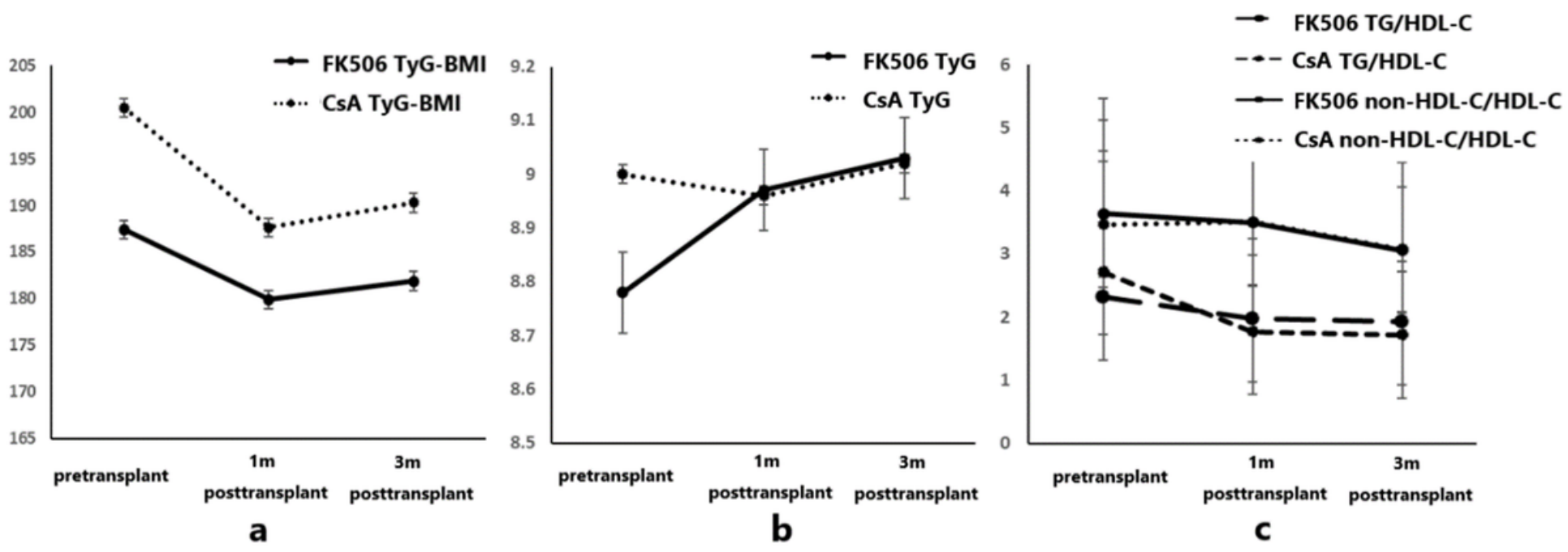

Figure 1

Changes of the markers at pretransplantation, $1 \mathrm{~m}$ posttransplantation and $3 \mathrm{~m}$ posttransplantation in FK506 and CsA subgroups. 

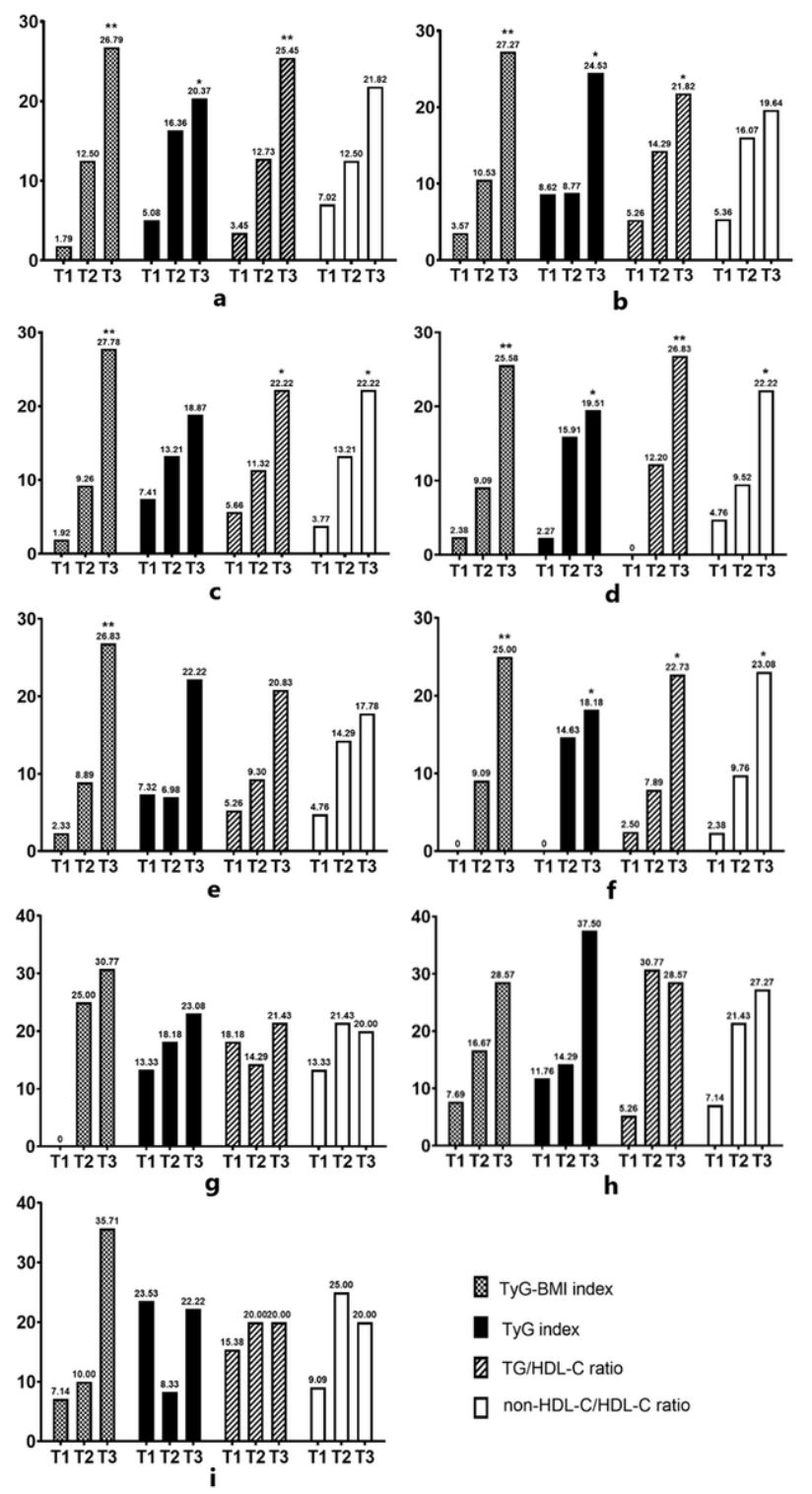

Figure 2

Comparisons of incidences of PTDM according to the trisections of the markers. 


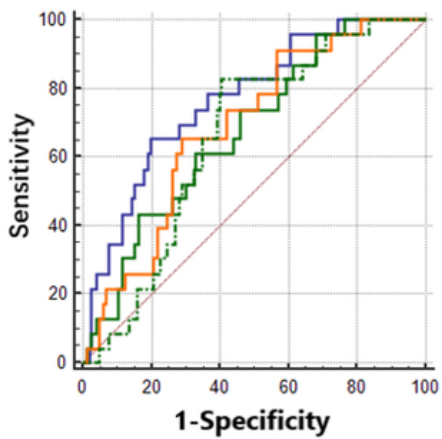

a
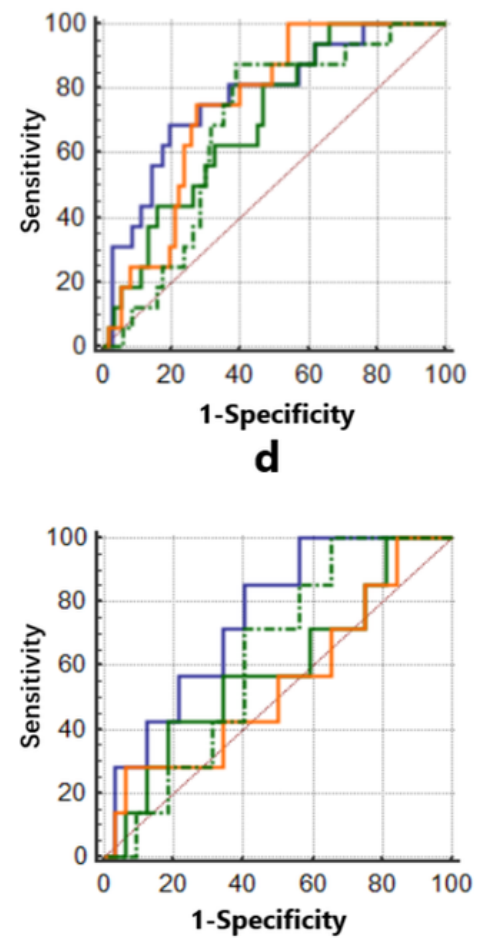

g

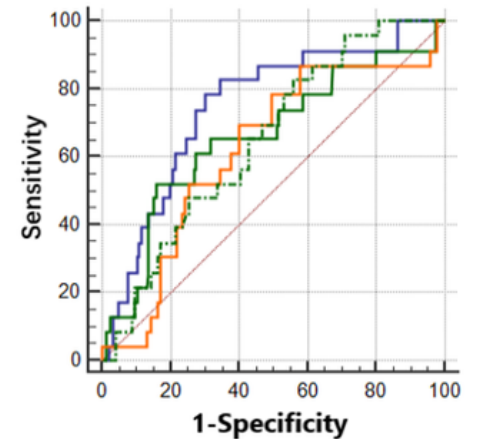

b
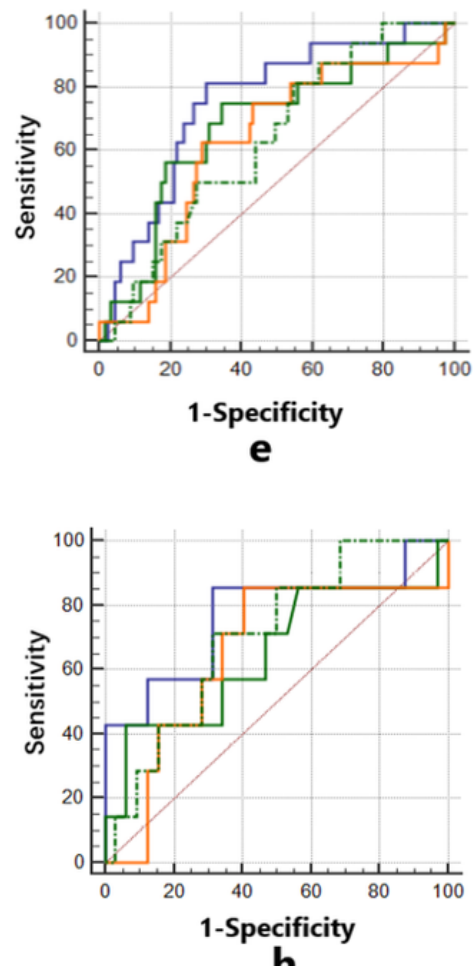

h

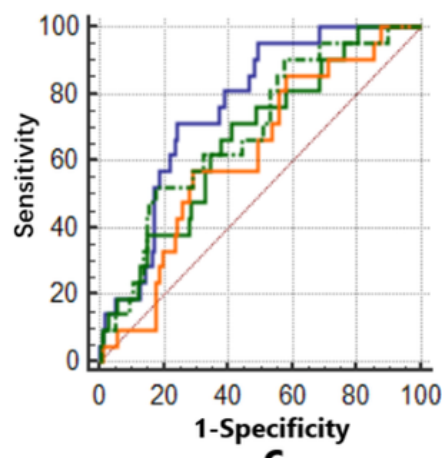

C
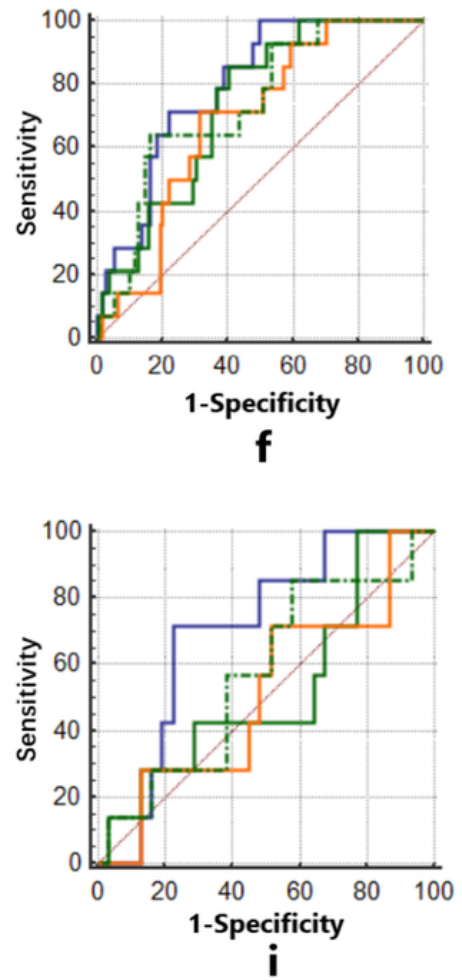

Figure 3

Comparison of AUCs of the markers. 